\title{
BRINCAR APRENDENDO OU APRENDER BRINCANDO? O INGLÊS NA INFÂNCIA
}

\section{LEARN THROUGH PLAYING OR PLAY THROUGHLEARNING? ENGLISHIN CHILDHOOD}

\author{
VERALUCIALOPES CRISTOVÃO* \\ RAQUEL GAMERO**
}

\begin{abstract}
RESUMO: A fim de contribuirmos para um debate significativo sobre o ensino de língua inglesa para crianças, temos como objetivo levantar questões a respeito desse ensino por meio da discussão do papel da língua inglesa na construção identitária de crianças e de proposições relativas à inclusão digital, à formação de professores ao uso de gêneros textuais e de atividade. Para fundamentar nossa proposta, apresentamos alguns conceitos relevantes: linguagem e identidade; o status da língua inglesa na sociedade brasileira contemporânea e as implicações para o ensino; a formação docente, gêneros de texto e gêneros de atividade. No trabalho, priorizamos a formação de professores de inglês para crianças.

Palavras-chave: ensino; formação de professores; língua inglesa para crianças; construção identitária; gêneros de texto e de atividade.
\end{abstract}

ABSTRACT: This paper aims at contributing to a significant debate about English language teaching for children. Our objective is to raise issues regarding the teaching of English in childhood by discussing the role of English in the construction of children's identities as well as statements related to digital inclusion, teacher education and the use of text and activity genres. To ground our proposal, we present some relevant concepts in order to situate our assumptions: language and identity; teacher education and text and activity genres.

Keywords: teaching; teacher education; English language for children; identity construction; text and activity genres.

\section{INTRODUÇÃO}

No cenário da formação de professores de língua inglesa (doravante LI), no Brasil, uma área tem sido destaque: a do ensino de inglês para crianças (TONELLI, 2007; ROCHA, 2007).

As escolas particulares incluem, facultativamente, o ensino de LI nas séries iniciais da educação básica e os institutos de línguas oferecem cursos de LI para crianças a partir dos três ou quatro anos de idade. A introdução à língua estrangeira em séries iniciais

\footnotetext{
*UEL, Londrina (PR), Brasil. <veracristovao@yahoo.com>

** UEL, Londrina (PR), Brasil. <rachelgamero@yahoo.com>
} 
também já se dá em algumas escolas municipais do país por iniciativas isoladas. Além dos contextos de ensino/aprendizagem formais, algumas crianças de nossa sociedade têm sido influenciadas pelo contato com a LI, que toma proporções diferentes daquela presente na sala de aula.

Por um lado, algumas crianças têm tido acesso a essa língua cada vez mais cedo, seja por intermédio de televisão, DVDs, CDs, internet, jogos eletrônicos; por outro, uma parcela de crianças de nossa sociedade não tem acesso a essa língua cuja falta assume caráter de exclusão social, principalmente, neste momento histórico em que se levantam tantas discussões e propostas para inclusão digital ${ }^{1}$.

Portanto, identificamos duas necessidades: 1) considerar especificidades que constituem o ensino de língua inglesa para crianças (doravante LIC); e 2) refletir sobre a oferta de programas de formação de professores que supra as lacunas geradas pela transformação social do uso e do ensino de LIC e proporcione inclusão.

Nossa proposta é levantar questões a respeito do ensino de inglês na infância por meio da discussão sobre: a) o papel da LI na constituição identitária de crianças; b) proposições relacionadas à inclusão digital e c) o uso de gêneros textuais e de atividade para refletirmos a respeito da formação de professores de inglês. Esperamos assim estar contribuindo para um debate profícuo acerca da educação infantil.

\section{INGLÊS NAINFÂNCIA: BRINCARAPRENDENDO OUAPRENDER BRINCANDO?}

Situamos nossa concepção de linguagem no quadro teórico-metodológico do interacionismo sociodiscursivo (BRONCKART, 1999, 2006) cuja base epistemológica está na concepção de que 'as condutas humanas' são construídas em um processo histórico de socialização, marcado, principalmente, pelo uso de artefatos simbólicos, como a linguagem, artefatos materiais, como um jogo, e determinado por dimensões sócio-históricas e culturais. Mais recentemente, Bronckart (2008) esclarece que sua visão de linguagem considera a linguagem como atividade significante. Dessa forma, linguagem é um meio de agir no mundo com suas bases interacionista, dialógica, comunicativa e materializada em uma língua que se constitui por um sistema de produções linguísticas caracterizadas por seu caráter sociocomunicativo. Para completar, ainda com base em Bronckart, defendemos que:

a linguagem desempenharia um papel fundamental e indispensável no desenvolvimento, considerando-se que é por meio dela que se constrói uma "memória" dos pré-construtos sociais e que é ela que organiza, comenta e regula o agir e as interações humanas, no quadro das quais são reproduzidos ou reelaborados os fatos sociais e os fatos psicológicos (CRISTOVÃO, 2008, p.5).

Ancoradas nesse conceito, partilhamos da noção de que o conhecimento é aprendido sempre em atividades coletivas sociais e mediadas por interações verbais. Assim, o agir

\footnotetext{
${ }^{1}$ Para a inclusão digital, o MEC define o banco internacional de objetos educacionais como um depósito de recursos em mídias diversas (áudio, vídeo, animação, imagem, hipertexto, softwares educacionais) com acesso público e livre para os diferentes níveis de ensino, inclusive à educação infantil. Recursos para educação infantil estão disponíveis em http://objetoseducacionais2.mec.gov.br/handle/mec/6163.
} 
comunicativo, constituído por ações de linguagem em práticas sociais situadas em esferas de atividade, se articula ao agir praxiológico, composto pelo agir prático que ajuda a construir a sociedade em seus três mundos: objetivo, social e subjetivo (BRONCKART, 2008).

Ao falarmos de ensino de LI, partimos do conceito de linguagem como determinante para as ações e interações humanas. Entendemos a língua como sócio-histórica, culturalmente desenvolvida e constitutiva de nossa identidade em constante transformação.

Rajagopalan (2003) utiliza termos que remetem a questões de identidade tidas como precárias e mutáveis, segundo as quais tudo é provisório e inacabado porque as pessoas renegociam na interação com o outro de forma dialógica. Para o autor, é na língua e pela língua que ocorre a expressão da identidade de quem dela se apropria.

Tendo como ponto de partida as concepções vygotskyanas segundo as quais as relações sociais no ambiente educacional são fatores essenciais para o desenvolvimento do indivíduo (PIMENTA e LIMA, 2004) afirmamos que "[...] o jogo é a forma natural de trabalho da criança, a forma de atividade que lhe é inerente, a preparação para a vida futura (VYGOTSKY, 1993, p. 107)”. A partir dessa citação, sustentamos que brincar/jogar é o gênero de atividade central e imprescindível da educação infantil. Os gêneros textuais têm o papel de instrumento/meio para a realização desse agir (brincar/jogar). Alguns gêneros que circulam na infância tanto na esfera cotidiana quanto na escolar podem ser histórias infantis, cantigas de roda, canções, rimas, parlendas, instruções/regras de jogo, entre outros.

Conforme definido por Bronckart (2006, p. 145), “[...] Os gêneros textuais, como configurações possíveis dos mecanismos estruturantes da textualidade, portadores de indexações sociais, constituem, como afirma Bakhtin (1984, p. 285), os quadros obrigatórios de qualquer produção verbal.” Em outras palavras, os gêneros são artefatos simbólicos que possibilitam a realização de ações em situações de comunicação específicas com percepção do contexto (quem, para quem, quando, onde, sobre o quê, como e para quê/por quê) e de artefatos materiais (linguísticos ${ }^{2}$, inclusive e principalmente). $\mathrm{O}$ ensino com base em gêneros teria como pressupostos que a aprendizagem desses artefatos tanto pode contribuir para seu agir no mundo como pode conferir ao aprendiz um senso de autoria, agência e autonomia possibilitando-lhe questionar aquele agir e/ou seu próprio artefato. Dessa forma,

A principal idéia defendida é a de que o desenvolvimento dos indivíduos ocorre em atividades sociais, em um meio constituído e organizado por diferentes pré-construídos e através de processos de mediação, sobretudo os linguageiros. Com isso, desde seu nascimento, eles podem ir se apropriando desses pré-construídos sociais, o que permite seu desenvolvimento e, dialeticamente, lhes permite contribuir para a transformação permanente dos préconstruídos. (MACHADO, 2009 )

Ancorados nesses construtos do interacionismo sociodiscursivo (ISD), buscamos a proposta da didática de línguas da Escola de Genebra (DOLZ et al., 2004, por exemplo). Como procedimento/dispositivo metodológico defende-se o uso de sequências didáticas que podem ser entendidas como um conjunto de atividades escolares organizadas, de

2 Tomamos língua como um sistema semiótico materializado em um código convencionalizado por características como sons, grafia, entre outros, que pode ser utilizado na interação entre seus usuários. 
maneira sistemática, em torno de um gênero textual oral ou escrito. Dessa forma, constituirse-iam por:

\section{Apresentação da situação:}

- dimensão do projeto coletivo (apresentação de problema de comunicação bem definido);

- dimensão dos conteúdos (percepção da importância dos conteúdos e conhecimento do projeto de classe para aprendizagem significativa e pertinente).

\section{Produção inicial}

- diagnóstico dos domínios e dificuldades e reguladora da SD;

- primeiro lugar de aprendizagem.

\section{Módulos (que possibilitam refacções)}

- trabalho com problemas de níveis diferentes (representação da situação de comunicação, por exemplo);

- variedade das atividades (atividades de observação e de produção; tarefas simplificadas);

- Aquisição de controle do próprio comportamento.

\section{Produção final}

- Possibilidade de agir com o uso dos instrumentos elaborados nos módulos.

Para a educação infantil, acreditamos que o uso de sequências didáticas para o ensino de inglês privilegiaria a produção e compreensão oral voltada para um agir significativo com a linguagem. Dito de outra forma, defendemos o jogo, a brincadeira e a vivência de experiências como formas de agir constitutivas da educação infantil. A sequência didática se voltaria para privilegiar esse agir (linguageiro e praxiológico) sustentado/possibilitado pela apreensão de gêneros textuais.

Nossa proposta é, portanto, o trabalho com gêneros textuais para ensino de LIC com a finalidade de construir valores para o desenvolvimento do indivíduo por meio de atividades lúdicas ${ }^{3}$. Assim, nos distanciaríamos de abordagens de ensino de LI voltadas para a aprendizagem de vocabulário, de fonética e de algumas frases para memorização.

Logo, precisamos nos perguntar que LI é esta que estamos ensinando e com que finalidade, visto que, sob condições favoráveis, a aprendizagem de LI na infância pode levar a criança a ampliar seus horizontes e romper barreiras culturais, evoluindo para uma aprendizagem efetiva, futuramente (ROCHA, 2007). Acreditamos, portanto, que crianças do nosso país tenham o direito a esta educação plena, na qual o inglês pode colaborar para a formação do indivíduo na atualidade, rumo à acessibilidade a informações e ao conhecimento.

${ }^{3}$ Compartilhamos do conceito de lúdico definido por Dantas (1998, p. 11 apud TONELLI, 2005) como "junção de brincar (forma livre e individual) e jogar (conduta social que supõe regras) com efeito prazeroso e alegre". 
A Organização das Nações Unidas (2003) defende que a Inclusão Digital (ID) é um meio para promover a melhoria da qualidade de vida, garantir maior liberdade social, gerar conhecimento e troca de informações. Esse é um fator tão relevante que a instituição considera a exclusão digital no mesmo patamar de exclusão da fome, do desemprego e do analfabetismo.

Para a Unesco e diversas instituições internacionais, hoje o conceito de analfabetismo vai muito além de não saber ler e escrever, englobando também o analfabetismo tecnológico, pois quem não domina as tecnologias é um excluído digital. Há hoje uma expressão utilizada para a falta de engajamento no "mundo digital": analfabetismo digital, que é entendido como grande fator de exclusão social. Dessa forma, entende-se como primordiais para uma participação efetiva na sociedade contemporânea as habilidades para utilizar programas de digitação (Word), correios eletrônicos (e-mails) e acessar a internet. A falta dessas habilidades, analfabetismo digital, afeta o aprendizado, a conectividade e a disseminação de informações.

Ramos (2007) afirma haver, inclusive por parte do governo brasileiro, um movimento em busca de equipamentos que possibilitem a acessibilidade digital em todos os contextos educacionais a fim de desenvolver programas de inclusão digital. "Pais, especialistas e professores concordam que as crianças devem ser alfabetizadas para o meio digital, a fim de que possam ser membros ativos e transformadores da sociedade em que vivem" (RAMOS, 2007, p. 65). A autora também defende que a inclusão de novas tecnologias pode trazer benefícios como desenvolvimento de diferentes estilos de aprendizagem, atendimento às múltiplas inteligências, fator motivador no ensino de LI, meio de encorajar a aprendizagem independente e pensamento criativo.

No entanto, para que haja melhoria na qualidade de ensino, apenas essa mobilização não é suficiente; é necessário que os professores sejam preparados e devidamente embasados teórico-metodologicamente, o que, segundo a autora, implica em mudanças: "O papel do professor como mediador da aprendizagem se concretiza quando este assume o desafio da inserção das novas tecnologias na sala de aula convencional" (RAMOS, 2007, p.74).

A autora alerta ainda para cuidados que o professor deve ter ao incluir esta proposta à sua prática: bloqueios a certos sites, vistoria feita aos e-mails que devem ser exclusivamente utilizados para a execução de atividades das aulas e conscientização das crianças a respeito dos riscos ao publicarem informações pessoais e abrirem e-mails de fontes desconhecidas, alertando-as para buscar orientação do professor antes de publicar material na internet.

A ascensão da língua inglesa ao status de língua franca, usada internacionalmente como meio de comunicação principalmente entre falantes não-nativos, tem trazido inúmeras implicações para seu ensino nas escolas (GIMENEZ et al, 2006). Canagarajah (1999) destaca que os alunos precisam questionar como a língua deve ser aprendida, e não se ela deve ser aprendida. Por um lado, quando há negociação crítica, é gerado o empoderamento; por outro, a recusa a aprender esse idioma como forma de defesa contra o que ele pode representar assume um caráter de exclusão.

Crawford (2007) foca as implicações que a expansão do inglês e a mudança do status dessa língua trouxeram para professores e formadores de professores, assim como as 
implicações destas supostas mudanças para as estratégias de ensino, os materiais e resultados que se busca alcançar.

Para colaborar com o debate a respeito da língua inglesa e seus conflitos, Gimenez (2006) direciona a discussão a um nível de políticas educacionais e à sala de aula.

Se por um lado o inglês está se distanciando, competitivamente, das outras línguas estrangeiras no mercado de línguas e, assim, criando uma "nova ordem linguística mundial" (GRADDOL, 2006), por outro está demandando definições quanto aos parâmetros que irão governar o ensino desta língua pelo mundo. (GIMENEZ, 2006, p. 61) (tradução nossa) ${ }^{4}$

Com base em Graddol (1997), Gimenez (2006) entende que a relação entre a globalização e o inglês é complexa, pois é um processo de inter-relação no qual não só o avanço do inglês fomenta a globalização, como também a globalização encoraja a disseminação do inglês. Esta relação (entre globalização e inglês) é permeada de ambiguidade: ao mesmo tempo em que os aprendizes encaram este processo como um novo modo de imperialismo, eles também almejam fazer parte desse processo. Nesse mesmo trabalho, a autora (GIMENEZ, 2006) argumenta que uma das consequências de se conceber o inglês como língua franca é que essa concepção tem de ser parte de políticas nacionais que venham a garantir o aprendizado para todos, o que implica a criação de escolhas pedagógicas adequadas a essa nova concepção.

Outro fator discutido pela autora é o fato de o inglês ser uma língua utilizada para a comunicação de diferentes povos, de diferentes línguas maternas, e as variedades a serem aceitas poderem ser muitas. Conflitos, que não existiam ao se tomar o nativo como modelo, passam a afligir o trabalho docente cujas opções pedagógicas diziam respeito ao preparo do aprendiz para comunicação com o nativo. O que também preocupa professores neste novo cenário é que parâmetros adotar e que decisões tomar em relação ao currículo. Neste caso, a autora sugere que todas as decisões devem ser tomadas em vista de uma análise do contexto de ensino, dos recursos disponíveis e de um olhar crítico para o que consideramos sucesso nesta língua.

Em outro trabalho, Gimenez et al (2006) afirmam que essa língua atrai a atenção dos jornais e revistas de grande circulação no país, trazendo a visão da classe média sobre a importância de conhecê-la, sendo ela frequentemente associada à perspectiva de oportunidades no mercado de trabalho. De acordo com os autores, todo este movimento tem gerado, recentemente, interesse pelo estudo dos efeitos dessas mensagens sobre as concepções de ensino/aprendizagem e sobre professores, o que tem revelado mitos, reforçados no discurso midiático, relacionados à eficácia ou não do ensino, e como essas concepções se tornam um termômetro para as escolhas de cursos de línguas e dos critérios de eficácia desse ensino. Essas imagens acabam por interferir nas salas de aula e por direcionar os objetivos que professores estabelecem. Isso implica a necessidade de se repensar o modo como o inglês vem sendo ensinado nas escolas, que cada vez mais é

\footnotetext{
${ }^{4}$ No original: if on one hand English is distancing itself from other foreign languages competing in the language market, therefore creating a "new world language order" (GRADDOL, 2006), on the other hand it is demanding definitions in terms of what parameters will govern the teaching of this language throughout the world.
} 
ajustada aos sentidos inseridos nele pela mídia. Para tanto, vale pensar que inglês é esse que ensinamos neste contexto sócio-histórico e cultural e qual é o objetivo de ensinar essa língua na contemporaneidade, pois pensar em falante de inglês como língua franca implica pensar que:

[...] os falantes de inglês como língua internacional devem ter as habilidades necessárias para lidar com as variedades de inglês, ou seja, ajuste de habilidades. Tal pressuposto nos leva a concluir que competência em inglês como língua internacional requer ser proficiente em ao menos uma variedade de inglês [...] (ACAR, 2007, p. 51) (tradução nossa).

Ao considerarmos esta "nova ordem linguística mundial” (GRADDOL, 2006; GIMENEZ, 2006) e o papel da língua inglesa na sociedade contemporânea, nos perguntamos quais são as implicações para o ensino e para a formação de professores neste novo cenário.

\section{AFORMAÇÃO DE PROFESSORES DE LIC}

PAIVA (2006) discorre sobre o panorama histórico da formação de professores para a educação infantil a fim de compreender e problematizar o espaço destinado à essa formação. Para a autora "formar o professor é estratégico, por atravessar todos os setores da sociedade e por conter, em seu âmago, a questão do projeto de sociedade que se almeja para o país, pois o professor molda gerações." ( p. 11)

Sabemos que a educação infantil tem objetivos diferenciados daqueles da educação básica, bem como perfis distintos dos do professor desse segmento. Para definir estes fatores peculiares, buscamos o Referencial Curricular Nacional para a Educação Infantil (BRASIL,1998), no qual se define o perfil desejado, qual seja, o de um professor que tenha competência polivalente. Essa polivalência implica um professor que possa lidar com conteúdos de naturezas diversas. Sendo assim, a formação profissional deve ser bastante ampla, além do que o professor deve estar em constante busca por conhecimento, ser reflexivo, debater com seus pares, dialogar com as famílias e a comunidade e buscar o conhecimento necessário para exercer sua profissão, tendo, como instrumentos essenciais para sua reflexão sobre a prática direta com as crianças, a observação, o registro, o planejamento e a avaliação.

Conforme o documento, a estrutura de formação da criança se apóia em uma organização por idades (crianças de zero a três anos e crianças de quatro a seis anos) e se concretiza em dois âmbitos de experiências: formação pessoal e social e conhecimento de mundo, que são constituídos pelos seguintes eixos de trabalho: identidade e autonomia, movimento, artes visuais, música, linguagem oral e escrita, natureza e sociedade, e matemática.

Segundo o referencial, não há aprendizagem sem conteúdos, portanto, outro fator de extrema importância é o conteúdo. As diferentes aprendizagens se dão por meio de constantes reorganizações do conhecimento e este processo é protagonizado pelas crianças

\footnotetext{
${ }^{5}$ No original: [...] the speakers of EIL should also have the necessary skills to cope with variability in English, that is, accommodation skills. Such assumptions lead us to conclude that competency in EIL would require being proficient in at least one variety of English, [...] (ACAR, 2007, p. 51)
} 
quando podem vivenciar experiências que lhes forneçam conteúdos apresentados de forma não simplificada e associados a práticas sociais reais. Esses conteúdos devem contemplar as seguintes categorias: conceituais, que dizem respeito ao conhecimento de conceitos, fatos e princípios; procedimentais, que se referem ao "saber fazer"; e atitudinais, associados a valores, atitudes e normas.

Quanto aos objetivos gerais da educação infantil, defende-se que a prática deve se organizar de modo que as crianças desenvolvam as seguintes capacidades:

- desenvolver uma imagem positiva de si, atuando de forma cada vez mais independente, com confiança em suas capacidades e percepção de suas limitações;

- descobrir e conhecer progressivamente seu próprio corpo, suas potencialidades e seus limites, desenvolvendo e valorizando hábitos de cuidado com a própria saúde e bem-estar; - estabelecer vínculos afetivos e de troca com adultos e crianças, fortalecendo sua autoestima e ampliando gradativamente suas possibilidades de comunicação e interação social; - estabelecer e ampliar cada vez mais as relações sociais, aprendendo aos poucos a articular seus interesses e pontos de vista com os demais, respeitando a diversidade e desenvolvendo atitudes de ajuda e colaboração;

- observar e explorar o ambiente com atitude de curiosidade, percebendo-se cada vez mais como integrante, dependente e agente transformador do meio ambiente e valorizando atitudes que contribuam para sua conservação;

- brincar, expressando emoções, sentimentos, pensamentos, desejos e necessidades;

- utilizar as diferentes linguagens (corporal, musical, plástica, oral e escrita) ajustadas às diferentes intenções e situações de comunicação, de forma a compreender e ser compreendido, expressar suas idéias, sentimentos, necessidades e desejos e avançar no seu processo de construção de significados, enriquecendo cada vez mais sua capacidade expressiva;

- conhecer algumas manifestações culturais, demonstrando atitudes de interesse, respeito e participação frente a elas e valorizando a diversidade (BRASIL, 1998, p. 63).

Entendemos que os objetivos propostos bem como os conteúdos de base conceitual, procedimental e atitudinal vem ao encontro de uma abordagem com base em gêneros na qual o agir (com a linguagem e em interações sociais diversas) é o alvo.

A fim de expor propostas voltadas à formação de professores para o ensino de LIC, tecemos um breve panorama sobre algumas publicações comumente utilizadas nas últimas duas décadas, a saber: Brumfit et al., (1991), Phillips (1993), Vale e Feunteun (1995), Slattery e Willis (2001), Matos (2004), bem como uma visão de cursos de licenciatura em inglês no Paraná.

Teaching English to Children: from Practice to Principle (BRUMFIT et al., 1991) é uma obra apresentada como provedora de base para o trabalho, por professores do ensino fundamental ${ }^{6}$ falantes nativos ou não, que traz como fundamentação teórica conceitos de Vygotsky e Piaget. A primeira parte do livro trabalha com a prática de ensino, contemplando sugestões que vão da prática à teoria. A segunda parte, contempla contexto de base, necessário para dar sentido aos princípios práticos, é mais teórica e apresenta conceitos acadêmicos, segundo as orientações do próprio material, que é defendido como possuidor de uma visão ampla da teoria e da prática, e cujo objetivo é oferecer exemplos de boa prática aos professores. A obra defende que os professores precisam primeiro da língua, dominando

${ }^{6}$ Tradução nossa: This book attempts to provide a basis for work by primary level teachers .... (p. iv) 
as competências básicas combinadas com metodologia de ensino e, segundo, de competências de metodologia para o ensino fundamental.

Na primeira seção, que aborda a prática de ensino, são contemplados os seguintes temas: uso da língua de forma significativa; aquisição de linguagem oral e escrita; compreensão do erro enquanto necessário para o aprendizado; trabalho com tarefas que as crianças encolhem para si mesmas; trabalho com professores que são envolvidos no processo, como pares mais experientes; leitura de literatura por prazer, com posicionamento crítico, e utilização desta leitura para o aprendizado.

Na segunda seção, teórica, são abordados temas relativos ao: sistema para o ensino de inglês para crianças; aprendizado de línguas (crianças); letramento infantil sob uma perspectiva internacional; letramento como experiência social; desenvolvimento do pensamento e da compreensão infantil, cultura e identidade da criança bilíngue; ensino de línguas para jovens aprendizes: padrões históricos; definição do syllabus.

Resource books for teachers: young learners (PHILLIPS,1993) é uma publicação dirigida ao ensino de jovens aprendizes (de 5/6 anos a 11/12 anos, não estritamente relacionado com a idade, mas com a maturidade do aprendiz), com objetivo de prover informações e atividades que venham ao encontro das necessidades de dois tipos de professores: das séries iniciais não-nativos, que podem não ser professores de língua capacitados, e por outro falantes nativos que não têm treinamento específico para o ensino infantil e para oferecer ideias e técnicas suplementares para suas salas de aula.

O livro é dividido em dez capítulos. Os cinco primeiros capítulos focam as quatro habilidades (listening, speaking, reading, writing) gramática e vocabulário; os capítulos de seis a nove abordam técnicas para uso específico em sala de aula (games, songs and chants, creative activities e video) e, por fim, o capítulo dez mostra como as atividades podem ser unificadas para formar uma unidade de trabalho.

Teaching Children English (VALE e FEUNTEUN, 1995) é uma publicação que se apresenta como um curso de treinamento para professores de inglês (nativos e não nativos; com ou sem experiência no ensino de inglês e/ou no ensino para crianças) a partir dos sete anos e como um recurso para os formadores. Enquanto recurso para a formação, o livro oferece conteúdo voltado para: a) conscientização das necessidades das crianças, da relação entre aprendizagem de LI e educação; b) orientação para gerenciamento da sala de aula, alternativas de dinâmicas, informações e usos de materiais, possibilidades de atividades; c) técnicas para o ensino de LE; d) atividades de proficiência linguística; e) oportunidades de intercâmbio de experiências; f) sessões de observação de aula; g) discussões sobre avaliação e pesquisa na e da sala de aula.

English for Primary Teachers (SLATTERY e WILLIS, 2001) é uma obra definida como guia de atividades e de linguagem da sala de aula. É voltada para professores de inglês (regentes, formadores, tutores) de crianças (de 4 a 12 anos) com trechos de aulas gravadas em diferentes partes do mundo e com atividades bem como técnicas para as aulas. Além disso, as unidades trazem excertos que enfocam o uso de inglês em sala de aula por professores em situação real. Como importante corpo de conhecimento, as autoras partem de algumas características típicas de crianças aprendizes que, segundo elas experimentam diversas estratégias de aprendizagem e estilos conforme o desafio proposto; testam seus limites e os do outro; gostam de repetição; têm tempo de concentração limitado, o que 
demanda variedade de atividades e de dinâmicas de interação; são curiosas; contam com a imitação (construtiva e não de mera reprodução) como parte do processo de aprendizagem; precisam de ação concreta e não de abstrações teóricas; tendem a partilhar suas experiências e conhecimentos como ponto de partida para novas construções; fazem constantes relações com sua realidade; valorizam suas conquistas e realizações; contam com sua língua materna para comparações, reflexões, partilhas, dúvidas etc.

Diante das características elencadas, a condução de aulas para crianças contemplada pelas unidades do livro cobre conteúdos em torno: a) do uso da língua inglesa e da língua materna em sala; b) da organização da aula e gestão da sala; c) do uso de instruções e enunciados ; d) de abordagens com jogos e outras atividades lúdicas; e) de práticas voltadas para a produção e compreensão oral e escrita; e f) de recursos que contribuem para o uso do inglês e o avanço na proficiência linguística.

Criatividade no ensino de inglês - A resourcebook (MATOS, 2004) é uma publicação nacional que oferece vinte atividades relacionadas ao ensino de vocabulário, à reflexão crítica e à formação geral do aprendiz em torno de questões como direitos linguísticos e cidadania. A proposta do autor se constitui por atividades lúdicas recheadas de humor e criatividade. Além disso, estimula a produção de novas atividades também de forma criativa e reflexiva como uma contribuição para a formação de professores de inglês.

Cada um dos livros supracitados têm relevância, em especial, se situados historicamente. Contudo, como já explicitamos, defendemos o trabalho com gêneros textuais para ensino de LIC e a construção de valores para o desenvolvimento do indivíduo por meio de atividades lúdicas. Desta forma, os livros descritos não estão em consonância com nossa proposta.

Os cursos de Letras com base nas Diretrizes Curriculares Nacionais para a Formação de Professores da Educação Básica (BRASIL, 2002) tem buscado formar profissionais com conhecimentos necessários para o desempenho da profissão, o que, segundo Richards (1998) e ratificado por Heberle e Meurer (2001), se concentram em seis dimensões que envolvem a atividade docente do professor de língua estrangeira: conhecimento teórico; habilidade de ensinar; habilidade comunicativa, que envolve habilidades gerais de comunicação, proficiência linguística e conhecimento prático; argumentação pedagógica e tomada de decisão e conhecimento contextual. Entendemos essas dimensões como gerais; entretanto, existem saberes específicos à educação infantil. Assim, temos que entender o professor de LIC inserido em um contexto social brasileiro, provenientes de uma determinada esfera social, e participante (ou não) do processo de interação digital.

Ao fazermos um levantamento sobre a grade curricular do curso de Letras, Pedagogia e cursos de especialização oferecidos em nosso estado, percebemos que estamos muito distantes de uma preparação adequada de nossos professores (seja a formação inicial seja a continuada) para este mercado em constante crescimento. Portanto, existe a necessidade de se pensar na inclusão de disciplinas que possam suprir as lacunas existentes entre a formação de professores de LI nas universidades e faculdades, e as necessidades peculiares dessa faixa etária. Segue quadro: 
Quadro 1: Universidades e disciplinas

\begin{tabular}{|c|c|c|c|}
\hline $\begin{array}{l}\text { UNIVERSIDADES } \\
\text { DO PARANÁ }\end{array}$ & $\begin{array}{l}\text { Letras: disciplinas que } \\
\text { contemplem o ensino de } \\
\text { LIC } 7\end{array}$ & $\begin{array}{l}\text { Pedagogia: disciplinas } \\
\text { que contemplem o } \\
\text { ensino de LIC }\end{array}$ & $\begin{array}{l}\text { CURSOS DE } \\
\text { ESPECIALIZAÇÃO } \\
\text { (LATO SENSU) }\end{array}$ \\
\hline $\begin{array}{c}\text { Pontifícia } \\
\text { Universidade Católica } \\
\text { (PUC/PR) }\end{array}$ & $\mathrm{X}$ & $\mathrm{X}$ & $\begin{array}{l}\text { Educação infantil } \\
\text { Língua Inglesa: metodologia } \\
\text { do ensino e tradução }\end{array}$ \\
\hline UEL & $\begin{array}{l}\text { Educação básica } \\
\text { Ensino de inglês para } \\
\text { crianças (eletiva) }\end{array}$ & $\mathrm{X}$ & $\begin{array}{c}\text { Ensino de inglês para crianças } \\
\text { Língua inglesa }\end{array}$ \\
\hline UEM & $\mathrm{X}$ & $\mathrm{X}$ & $\begin{array}{l}\text { Gestão de políticas para a } \\
\text { criança e juventude }\end{array}$ \\
\hline UEPG & $\mathrm{X}$ & $\mathrm{X}$ & $\begin{array}{l}\text { Ensino Aprendizagem de LE } \\
\text { Educação infantil e séries } \\
\text { iniciais do ensino fundamental }\end{array}$ \\
\hline UFPR & $\mathrm{X}$ & $\mathrm{X}$ & $\mathrm{X}$ \\
\hline UNIOESTE & $\mathrm{X}$ & $\mathrm{X}$ & $X$ \\
\hline UTFPR & $\mathrm{X}$ & $\mathrm{X}$ & $X$ \\
\hline UNOPAR & $\mathrm{X}$ & $\mathrm{X}$ & $\begin{array}{c}\text { Língua inglesa para o ensino } \\
\text { fundamental e médio (Campus } \\
\text { Arapongas) }\end{array}$ \\
\hline
\end{tabular}

Podemos concluir que a educação inicial no curso de Letras está voltada para a aprendizagem de inglês, literatura de língua inglesa e prática de ensino. A atuação do profissional prioriza o campo da educação básica a partir do $6^{\circ}$ ano do ensino fundamental. Já o curso de Pedagogia está voltado para a aprendizagem de conhecimentos relativos à didática e à psicologia da educação para as séries iniciais do ensino fundamental.

Considerando a importância da formação profissional e seu impacto na identidade dos professores somos levados a avaliar que a falta de formação específica pode colaborar para que haja docentes inseguros em sua prática (ROSSI, 2008), o que reforça nosso argumento da necessidade da inserção de formação de professores de LIC no ensino superior.

\section{RETROSPECTIVA DE PESQUISAS RELACIONADAS AOS TEMAS AQUI DISCUTIDOS}

Mais do que reconceituar a concepção da língua inglesa na esfera acadêmica, é necessário levar essa discussão à esfera política, porquanto, em se tratando de política de ensino de línguas estrangeiras no Brasil, incluem-se conceitos como identidade, cultura, ideologia, desenvolvimento educacional, legislação, ética, etc. (BOHN, 2000). Na sequência, apresentamos uma retrospectiva de pesquisas relacionadas a alguns desses temas.

Miranda (2003) fundamenta-se em Vygotsky e Bakhtin para elaborar sua pesquisa e discutir o papel do aluno e do professor em sala de aula, considerando que a constituição

${ }^{7}$ Língua inglesa para crianças. 
do indivíduo acontece em sua relação com o mundo e na sua inserção em um contexto histórico-cultural.

A autora aborda a perspectiva sócio-histórica de Vygotsky para conceituar o indivíduo como um ser que age em um mundo social, histórico e culturalmente construído. E por constituir-se um ser social, tem necessidades e interesses que devem ser privilegiados pelo processo de ensino-aprendizagem, em consonância com o momento histórico em que vive e em função de suas características socioculturais.

Um dos conceitos fundamentais dessa abordagem, segundo a autora, é a ação humana mediada por instrumentos que estão a sua disposição por meio da participação em contextos sociais. Além de partilhar da visão de Bakhtin quanto ao uso da língua, a pesquisadora pressupõe a visão de que a aprendizagem de língua ocorre por intermédio do uso da linguagem em situações de interação significativas com outras pessoas e, portanto, o sujeito se constitui na e pela linguagem.

Desse modo, é imprescindível que se considere a realidade do aluno, ser social em sala de aula, focando-se a interação e compreendendo-se o ensino/aprendizagem como um processo social, histórico e cultural, como uma forma de socialização da língua entre indivíduos (VYGOTSKY, 1933). Como o aluno deverá ser capaz de agir no mundo, o aprendizado vai-se construindo de forma contextualizada.

Miranda (2003) desenvolve seu trabalho sob a premissa da brincadeira enquanto atividade no processo de ensino/aprendizagem. Como um conceito vygotskyano, a brincadeira é compreendida como fundamental para a inserção social do indivíduo, pois é brincando que a criança amplia a zona de desenvolvimento proximal. Ao brincar, as crianças em idade escolar buscam satisfazer necessidades que são o motivo de suas ações, motivos estes que variam de acordo com a idade, mas, segundo a autora, o interesse continua sendo um aspecto importante na colocação da brincadeira como uma forma de atividade. A criança passa a utilizar o brinquedo como meio de realização de desejos não realizáveis de imediato. É no brinquedo que estão embutidas as regras ${ }^{8}$ de comportamento para conseguir jogar e realizar aqueles desejos. E é por intermédio do brincar que as crianças podem adquirir tais regras.

No estudo apresentado pela autora, os tipos de atividades tinham como propósito propiciar um aprendizado centrado na ação das crianças ao brincarem e, assim, tentar ampliar uma zona proximal de desenvolvimento, propondo a brincadeira como atividade com o objetivo de possibilitar ações mais significativas para as crianças.

A partir de sua pesquisa, Miranda (2003) conclui que as participações dos alunos e da professora, nas aulas de inglês, sob a perspectiva sócio-histórica, revelaram-nos como sujeitos coconstrutores dos saberes do grupo, que se constituem na e pela linguagem, necessitando do outro e de sua cultura para que haja mediação e conflito para a ampliação de uma zona de construção de conhecimento.

Pires (2004) desenvolve um estudo de caso a respeito do aprendizado de inglês na idade pré-escolar. Seu cenário inicial parte de duas problemáticas: a falta de material didático apropriado para essa faixa etária, bem como a falta de professores com qualificação profissional específica para o ensino de LIC. Sua pesquisa revela que o professor é formado

\footnotetext{
${ }^{8}$ Vygotsky afirma que não há brinquedo (brincadeira) sem regras.
} 
para o ensino de línguas, mas falta-lhe experiência com educação infantil (podendo gerar nas crianças aversão à língua); ou tem as habilidades necessárias para o trabalho na educação infantil, mas conhecimentos linguísticos escassos (podendo gerar nas crianças uma atitude de valoração do erro como verdade absoluta). Para a autora, ambos os casos representam risco para a continuidade da aprendizagem dessa língua futuramente.

Nesse estudo, a autora apresenta fatores biológicos favoráveis ao aprendizado precoce da língua estrangeira, referindo-se à percepção fonética, afirmando que o aluno seria, portanto, capaz de adquirir a língua com fluência e pronúncias próximas à de um falante nativo. Entretanto, voltemos à questão da língua: se compreendemos hoje, nesta nova ordem mundial, que o inglês tomou proporções distintas das que tinha enquanto língua estrangeira e que, portanto, não pertence a povo algum, que pronúncia é a que queremos ensinar às crianças? E que falante é esse a ser imitado?

Se o aluno vai reproduzir a pronúncia desses professores, concordamos com o posicionamento da autora que considera essa exposição um risco para o futuro aprendizado da criança por acreditarmos que o professor de LIC deve ser altamente qualificado tanto no que diz respeito aos conhecimentos pedagógicos, didáticos e estético-culturais relevantes para a interação com a criança quanto aos conhecimentos especificamente relacionados ao ensino de LIC (como conteúdo linguístico, procedimentos metodológicos sobre ensino de língua estrangeira, entre outros).

Outro trabalho de investigação é a pesquisa de mestrado desenvolvida por Tonelli (2005) na qual defende que o aspecto lúdico contribuiu grandemente para o ensino/ aprendizagem de LI. A autora ressalta que, pelo fato das crianças terem necessidade de fantasia e de imaginação, o gênero história infantil supre essa necessidade, desencadeando um processo de apropriação e uso para construção de conceitos e conhecimentos. A pesquisadora relata sua necessidade de se apropriar de tal gênero, para que possa identificar suas características e assim seja capaz de transpô-lo ao ensino de LI. Na pesquisa de Tonelli, as crianças foram capazes de trazer para as aulas de LI seu conhecimento de mundo, o que possibilitou o uso da língua de forma significativa e contextualizada.

Aproximando-se de nossa proposta em trabalhar com gêneros textuais orais para o ensino de LIC, Cordeiro (2009) apresenta uma análise de produções do gênero oral "receita de cozinha", em um estudo comparativo longitudinal durante dois anos letivos, da educação infantil em Genebra.

Foram apresentados como objetivos: realizar uma discussão sobre o lugar dos gêneros textuais formais no ensino da linguagem oral no ciclo da educação infantil e a análise de indicadores de progressão das capacidades de linguagem dos alunos de um ano a outro da escolaridade. Segundo a autora, os resultados da pesquisa, indicam que os gêneros textuais orais formais podem constituir objeto de ensino/aprendizagem pertinente em classes de educação infantil.

Neste ensaio, corroboramos a proposta de um ensino de língua com base em gênero, no entanto, sendo este um instrumento para o saber fazer. Assim, diferentemente do trabalho de Cordeiro para francês como língua materna, defendemos para LIC que o saber dizer não seria um objeto de ensino, mas constituiria a atividade realizada, o agir alvo da aprendizagem. 


\section{CONSIDERAÇÕES FINAIS}

As novas tecnologias levaram nossas crianças a um estado de inquietação constante, já que essa geração de nativos eletrônicos vivencia o mundo de forma muito dinâmica. Portanto, o professor de educação infantil precisa trabalhar fatores motivacionais que possam contribuir para um processo que envolva descoberta, interação, desafio e convivência com as tecnologias dessa nova geração. Um caminho é a utilização de gêneros textuais como mediadores das atividades lúdicas que possibilitam às crianças agirem, interagirem e (re) construírem conhecimentos que respeitem seus interesses e contribuam para sua formação identitária.

Há, portanto, um empenho na busca de gêneros que contribuam para a formação integral da criança e propiciem o instrumento para seu agir no jogo ou na brincadeira, bem como para seu desenvolvimento motor, social, emocional, afetivo, etc. na relação com o outro.

As implicações sociais discutidas neste texto são, de certa forma, compartilhadas por Rocha (2007) que defende o trabalho com gêneros como proposta pedagógica, como alternativa para se trabalhar a formação plena do indivíduo, além de tratar de aspectos sociais e políticos que constituem nosso agir no mundo.

O agir com a linguagem na educação infantil é um agir voltado para o lúdico - a brincadeira, o jogo, a vivência social de experiências, que promovem a aprendizagem. É na brincadeira que a aprendizagem ocorre e possibilita o desenvolvimento.

A fim de ilustrar uma possibilidade de atividade voltada ao objetivo de utilizar diferentes linguagens (musical, oral e língua estrangeira), apresentamos a ressignificação de uma proposta baseada em Morino e Faria (2007). A turma de pequenos aprendizes e a professora optaram por assistirem a um filme e fazer pipoca para rechear a sessão. O desafio é que usando a música e a língua estrangeira, os alunos possam aprender a fazer pipoca de microondas a partir de uma música que apresenta as instruções:

\section{It's easy! It's easy! \\ Open the microwave \\ Put the popcorn in \\ Press 3 minutes \\ Wait and see... \\ It's ready! Let's eat it!}

Hum! Delicioussssssssss!

Assim, cantando Making Popcorn, crianças de cinco e seis anos aprendem os procedimentos necessários para fazerem pipoca de microondas, de forma lúdica e significativa. O objetivo final não foi aprender a canção e sim comer a pipoca na sessão cinema.

Portanto, reforçamos que o saber fazer em atividades lúdicas por meio da língua estrangeira seria o alvo do ensino de LIC na infância. Os jogos e as brincadeiras são privilegiados ao mesmo tempo em que possibilitam diversas aprendizagens de cunho atitudinal, procedimental e conceitual. O saber dizer, tendo os gêneros textuais como foco 
da aprendizagem, seria trabalhado a partir do ensino fundamental para que progressivamente o saber fazer e o saber dizer fossem constituídos de forma indissociavel.

\section{REFERÊNCIAS BIBLIOGRÁFICAS}

ACAR, A. (2007). Standards and Competence in English as an International Language Pedagogy. Asian EFL Journal, vol. 9, no. 4: Conference Proceedings. 2007, p. 39-53.

BEATO, Z. (2004). Identidades e suas Impossibilidades. In: Trabalhos em lingüística aplicada, Campinas, (43): p. 159-170, Jan./Jun.

BOHN, H. (2000). Os aspectos 'políticos' de uma política de ensino de línguas e literaturas estrangeiras. Linguagem e Ensino. Pelotas, v.3, n.1, 2000, p.117-138.

BRASIL. (1998). Ministério da Educação e do Desporto. Secretaria de Educação Fundamental. Referencial curricular nacional para a educação infantil / Ministério da Educação e do Desporto, Secretaria de Educação Fundamental. — Brasília: MEC/SEF.

(2002). Resolução CNE/CP1, de 18 de fevereiro de 2002. Institui Diretrizes Curriculares Nacionais para a Formação de Professores da Educação Básica, em nível superior, curso de licenciatura, de graduação plena. Conselho Nacional de Educação, Brasília, 18 fev.

BRONCKART, J.P. (1999). Atividade de linguagem, textos e discursos: por um interacionismo sóciodiscursivo. São Paulo: EDUC.

(2006). Atividade de linguagem, discurso e desenvolvimento humano. Campinas: Mercado das Letras.

(2008a). O Agir nos discursos: das concepções teóricas às concepções dos trabalhadores. Campina: Mercado de Letras. (Série idéias sobre a linguagem).

BRUMFIT, C.; MOON, J.; TONGUE, R. (1991). Teaching English to Children: from Practice to Principle.London: Collins ELT.

CANAGARAJAH, A. S. (1999). Resisting linguistic imperialism in English teaching. Oxford University Press.

CORDEIRO, G. S. (2009). Ensino da linguagem oral na educação infantil: o lugar dos gêneros textuais formais. In: SIMPÓSIO INTERNACIONAL DE ESTUDOS DE GÊNEROS TEXTUAIS, 5, 2009, Caxias do Sul. Anais: Caxias do Sul.

CRAWFORD, J.C. (2005). English as a lingua franca: Implications for the teacher education programs. In: 22 International Conference on English Teaching and Learning in the Republic of China. June 2005, National Taiwan Normal University, Taipei, Taiwan.

CRISTOVÃO, V.L.L. (2008). Interacionismo sociodiscursivo (ISD): Quadro teórico-metodológico para estudos da linguagem. In: CRISTOVÃO, V. L. L.(org.) Estudos da Linguagem à luz do interacionismo sociodiscursivo. Londrina: UEL.

DEWEY. M. (2007). English as a lingua franca and globalization: an interconnected perspective. International Journal of Applied Linguistics. v. 17, n.3. p. 332-354.

DOLZ, J.; NOVERRAZ, M.; SCHNEUWLY, B. (2004). Seqüências didáticas para o oral e a escrita: apresentação de um procedimento. In: ROXO, R.; CORDEIRO, G. S. Campinas, Mercado de Letras. pp. 95-128. 
GIMENEZ, T. (2006). English in a new world language order. In: Loreni Machado; Vera Lúcia Lopes Cristovão; Viviane Bagio Furtoso. (Org.). Aspectos da linguagem: considerações teórico-práticas. Londrina: Universidade Estadual de Londrina. p. 59-71.

GIMENEZ, T.; SERAFIM, J. S.; SALLES, M. R.; ALONSO, T. (2006). Referências recentes sobre língua inglesa, mídia e escola no contexto brasileiro. Linguagem \& Ensino, Pelotas, v. 9, n. 1, p. 251-266, jan./jun.

GRADDOL, D. (2006). English Next. London: British Council.

HEBERLE, V. M; MEURER, J. L. (2001). In: FORTKAMP, M.B.M; XAVIER, R.P. (ed.). EFL teaching and learning in Brazil, theory \& practice. Florianopolis: INSULAR.

MACHADO, A. R. (2009). Linguagem e Educação: o ensino e aprendizagem de gêneros textuais. In:ABREU-TARDELLI, L. S. (Org.) ; CRISTOVÃO, V. L. L. (Org.) . 1a.. ed. Campinas: Mercado de Letras.

MATOS, F. C. G. (2004). CriAtividade no Ensino de Inglês - A resourcebook. São Paulo: Disal.

MIRANDA, A.V. (2003). Ensino de Inglês para Crianças: A Participação dos Alunos e Professora na Construção do Conhecimento. Dissertação (Mestrado em Lingüística Aplicada ao Ensino de Línguas) - Pontifícia Universidade Católica de São Paulo, Conselho Nacional de Desenvolvimento Científico e Tecnológico.

MORINO, E. C.; FARIA, R. B. (2007). Hello!1. ano do Ensino Fundamental. São Paulo: Editora Ática.

MOTA, A. L. B. (2007). Criança e mídia: o acesso ao computador e seus reflexos nos saberes da criança de educação infantil. Dissertação (mestrado) - Universidade Federal do Paraná, Setor de Educação, Programa de Pós-Graduação em Educação. Disponível em: http://dspace.c3sl.ufpr.br/dspace/handle/ $\underline{1884 / 12067 ? \text { mode }=\text { full }}$

PAIVA, F. S. (2006). formação do professor da educação infantil e séries iniciais do ensino fundamental no Brasil: avanços ou recuos? Políticas educativas na América Latina: consequiências sobre a formação e o trabalho docente. Seminário da Redestrado - Regulação Educacional e Trabalho Docente. VI , Rio de Janeiro. Anais...: Rio de Janeiro: UERJ,2006, p. 1-14.

PHILLIPS, S. (1993). Resource Books for Teachers: Young Learners. Oxford: Oxford University Press.

PIMENTA, S. G; LIMA, M. S. L. (2004). Estágio e Docência. São Paulo: Editora Cortez.

PIRES, S. S. (2004). Ensino de Inglês na Educação Infantil. In: SARMENTO, S; MÜLLER, V. (org.). $O$ Ensino de Inglês como língua estrangeira: estudos e reflexões. Porto Alegre: APIRS. p. 19-42.

RAJAGOPALAN, K. (2003). A identidade lingüística em um mundo globalizado. In: Rajagopalan, K. Por uma lingüística crítica: linguagem, identidade e a questão ética. São Paulo: Parábola Editorial. p. $57-63$.

RAMOS, S. G. M. (2007). A internet e suas contribuições ao ensino de inglês para crianças. In: TONELLI, J. R. A. e RAMOS, S. G. M. (org.). O ensino de LE para crianças: reflexões e contribuições. Londrina: Moriá. p. 61-75.

REZENDE L. (2005). O processo de alfabetização inserido em projetos de inclusão digital: uma análise crítica. In Proceedings CINFORM - Encontro Nacional de Ciência da Informação VI, Salvador. Disponível em: http://www.cinform.ufba.br/vi_anais/docs/LauraRezende.pdf 
RICHARDS, J. (1998). Beyond training. Cambridge: Cambridge University Press.

ROCHA, C. H. (2007). O ensino de LE (inglês) para crianças do ensino fundamental público na transdisciplinaridade da lingüística aplicada. In: TONELLI, J. R. A. e RAMOS, S. G. M. (org.). $O$ ensino de LE para crianças: reflexões e contribuições. Londrina: Moriá. p. 1-34.

ROSSI, E. C. S. (2008). Valores de verdade sobre a formação e a identidade do professor. In: CRISTOVÃO, V. L. L.(org.) Estudos da Linguagem à luz do interacionismo sociodiscursivo. Londrina: UEL.

SANTOS, R. S. (2005). A inclusão digital requer novo pacto social entre governos e sociedade. Inclusão Social, vol. 1, n. 1. disponível em: http://revista.ibict.br/inclusao/index.php/inclusao/article/view/ $\underline{1 / 1}$

SLATTERY, M; WILlIS, J. (2001). English for Primary Teachers. Oxford: Oxford University Press.

TONELLI, J. R. A. e RAMOS, S. G. M. (org.). (2007). O ensino de LE para crianças: reflexões e contribuições. Londrina: Moriá.

UNESCO. www.unesco.org.br, ONU 2003.

VALE, D.; FEUnTEUn, A. (1995). Teaching Children English: A Training Course for Teachers of English to Children. Melbourne: Cambridge University Press.

VYGOTSKY, L. S. (1934) Pensamento e Linguagem. Trad. Jeferson Luiz Camargo. São Paulo: Martins Fontes, 1993. 